\title{
HUBUNGAN TIONGKOK DAN SUNDA DALAM NASKAH-NASKAH SUNDA KUNO: KEARIFAN LOKAL DALAM MENJAGA KEUTUHAN BANGSA INDONESIA
}

\author{
Mamat Ruhimat \\ Prodi D4 Bahasa dan Budaya Tiongkok Fakultas Ilmu Budaya Universitas Padjadjaran \\ Email: mamat.ruhimat@unpad.ac.id
}

\begin{abstract}
Abstrak
Naskah-naskah kuno merupakan warisan budaya nenek moyang bangsa Indonesia yang mengandung kearifan lokal untuk digali dan dijadikan acuan bagi kehidupan generasi penerusnya. Naskah-naskah Sunda Kuno yang ditulis pada abad ke-16 dan 17 Masehi menunjukkan bukti-bukti hubungan baik antara Tiongkok dengan Sunda pada masa itu, bahkan jauh sebelum abad ke-7 Masehi.Nuansa isi naskah Sunda Kuno pada umumnya berupa ajaran kehidupan yang menjadi pegangan masyarakat Sunda pada masa itu. Naskah-naskah tersebut adalah: Sewaka Darma (SD), Sanghyang Siksakandang Karesian (SSK), Amanat Galunggung (AM) , Sri Ajnyana (SA), Bujangga Manik (BM), Darma Jati (DJ), Kawih Pangeuyeukan (KP), Carita Parahiyangan (CP), dan Carita Ratu Pakuan (CRP).Studi pustaka dalam penelitian ini terhadap naskah-naskah Sunda Kuno yang telah melalui tahap penelitian filologis dan diterbitkan dalam bentuk edisi teks dan terjemahan. Pengumpulan data dari naskah-naskah tersebut difokuskan pada teks-teks yang menyebut nama Cina. Selanjutnya data tersebut diklasifikasikan berdasarkan kelompok bahasa, bangsa, produk, dan keahlian.

Pengetahuan masyarakat Sunda pada abad ke-16 dan 17 tentang Tiongkok membuktikan bahwa mereka telah saling mengenal melalui bahasa, peradaban, produk-produk berkualitas tinggi, politik, dan kepandaian. Produk-produk berkualitas tinggi dari Tiongkok merupakan data yang paling banyak ditemukan dalam naskah Sunda Kuno. Ini menunjukkan bahwa hubungan perdagangan merupakan aspek yang sangat maju pada saat itu. Keharmonisan hubungan Tiongkok dan Sunda seperti yang tercatat dalam naskah-naskah Sunda Kuno merupakan kearifan lokal yang sudah sepantasnya digali dan diterapkan dalam kehidupan berbangsa dan bernegara. Kearifan lokal ini menjadi sangat penting ketika bangsa Indonesia sedang menghadapi krisis mental dalam mempertahankan persatuan dan kesatuan bangsa demi tegaknya keutuhan Negara Kesatuan Republik Indonesia.
\end{abstract}

Kata Kunci: naskah kuno,kKearifan lokal, keutuhan bangsa

\section{A. PENDAHULUAN}

Hubungan Tiongkok dengan Sunda telah terjalin selama ribuan tahun. Berita dari zaman Dinasti T'ang abad ke-7 Masehi menyebutkan bahwa sampai tahun 669 kerajaan Tolomo (Tarumanegara) masih mengirimkan utusan-utusannya ke Tiongkok (Soekmono, 1973:39). Dari berita tersebut dapat dikatakan bahwa hubungan yang erat antara Tiongkok dengan Sunda tentu sudah lebih terjalin sebelum abad ketujuh Masehi. Bukti-bukti keberlanjutan hubungan Tiongkok 
dengan Sunda dapat ditelusuri pula melalui peninggalan nenek moyang orang Sunda yang tertulis pada naskah-naskah Sunda Kuno. Naskah-naskah Sunda Kuno yang umumnya menggunakan daun lontar dan berbahasa Sunda Kuno tersebut ditulis antara abad ke-16 dan 17 Masehi. Naskah-naskah tersebut sebagian besar mengungkapkan perihal kehidupan masyarakat Sunda pada masa lalu, jauh sebelum dan ketika naskah tersebut ditulis.

Sebagai salah satu bukti tertulis kebudayaan masa lalu, naskah-naskah tersebut tentu saja dapat dijadikan sumber utama untuk menyusun sejarah kebudayaan suatu bangsa, khususnya sejarah kebudayaan Sunda dan hubungannya dengan Tiongkok. Dengan adanya bukti tertulis pada naskahnaskah kuno, nilai kesejarahannya pun akan lebih dapat dipertanggungjawabkan secara ilmiah. Penelitian naskah-naskah Sunda Kuno yang berkaitan dengan Tiongkok, salah satunya bertujuan untuk menggali kearifan lokal dalam kedekatan hubungan antara kedua bangsa ini. Apalagi pada akhir-akhir ini ada kecenderungan terjadi isu-isu negatif yang mulai mengancam keharmonisan hubungan yang telah terjalin ribuan tahun tersebut. Isu-isu negatif sama sekali tidak ditemukan di dalam naskah Sunda Kuno. Akan tetapi, beberapa peristiwa yang terjadi pada masa Kolonial Hindia Belanda dapat menjadi patokan bahwa pertikaian antara etnik Tionghoa dengan pribumi merupakan salah satu politik penjajah untuk memecah belah dan menghancurkan bangsa. Pada tahun 1832 terjadi peperangan antara pendatang dari Tionghoa dengan pasukan Kolonial Belanda dan pribumi yang terjadi di Purwakarta (Suriadiraja, 1932:111). Semenjak saat itu, kehidupan antara warga Tionghoa dengan pribumi mulai kurang harmonis dan seolah-olah ada batas yang memisahkan kehidupan keduanya dalam bermasyarakat. Keaadaan tersebut berlanjut hingga keruntuhan Orde Baru. Pada Orde Reformasi, usaha-usaha untuk mengharmoniskan hubungan warga Tionghoa dengan pribumi tersu dilakukan, namunmasih saja ada pihak-pihak yang mencoba menggagalkan usaha tersebut. Oleh karena itu, melalui kajian naskah-naskah kuno dapatlah kita mengambil pelajaran yang berharga dari nenek moyang kita, bahwa sejak dahulu kala hubungan Tiongkok dengan warga pribumi, khususnya orang Sunda, telah terjalin dengan sangat baik dan harmonis.

Objek yang digunakan dalam penelitian ini adalah naskah-naskah Sunda Kuno yang umumnya berasal dari abad ke-16 dan 17 yang tersimpan pada koleksi museum, perpustakaan, dan cagar budaya di wilayah Tatar Sunda. Bentuk penyajian teks dari naskah-naskah ini adalah puisi dan prosa. Nuansa isi naskah pada umumnya berupa ajaran kehidupan yang menjadi pegangan masyarakat Sunda pada masa itu. Naskah-naskah tersebut adalah: Sewaka Darma (SD), Sanghyang 
Siksakandang Karesian (SSK), Amanat Galunggung (AM), Sri Ajnyana (SA), Bujangga Manik (BM), Darma Jati (DJ), Kawih Pangeuyeukan (KP), Carita Parahiyangan (CP), dan Carita Ratu Pakuan (CRP).

Metode yang digunakan dalam penelitian ini adalah studi pustaka terhadap naskah-naskah Sunda Kuno yangtelah melalui tahap penelitian filologis dan diterbitkan dalam bentuk edisi teks dan terjemahan. Pengumpulan data dari naskah-naskah tersebut difokuskan pada teks-teks yang menyebut nama Cina. Selanjutnya data tersebut diklasifikasikan berdasarkan kelompok bahasa, bangsa, produk, dan keahlian.

\section{B. Pembahasan}

Hasil pengumpulan dan klasifikasi data menunjukkan bahwa hubungan Tiongkok dengan Sunda telah terjalin dalam berbagai aspek kehidupan yang harmonis. Pengetahuan masyarakat Sunda pada abad ke-16 dan 17 tentang Tiongkok membuktikan bahwa mereka telah saling mengenal melalui bahasa, peradaban, produk-produk berkualitas tinggi, politik, dan kepandaian. Produk-produk berkualitas tinggi dari Tiongkok merupakan data yang paling banyak ditemukan dalam naskah Sunda Kuno. Ini menunjukkan bahwa hubungan perdagangan merupakan aspek yang sangat maju pada saat itu. Bahkan, di dalam imajinasi penulis naskah, produk-produk bernilai tinggi tersebut digunakan untuk melengkapi keindahan istana dan rumah-rumah di surga atau kayangan.

\section{Bahasa Cina}

Naskah Sanghyang Siksakandang Karesian (SSK) yang ditulis pada tahun 1518 Masehi menjelaskan tentang bahasa-bahasa yang digunakan dalam pergaulan antarbangsa di Tatar Sunda pada saat itu. Ada 55 bahasa yang disebutkan dlam naskah tersebut. Bahasa Cina merupakan bahasa yang pertama disebutkan. Hal ini menunjukkan bahwa bahasa Cina merupakan bahasa yang paling banyak dipakai dalam pergaulan, terutama dalam urusan perdagangan.

Lamun dek nyaho di carek paranusa ma: carek Cina, Keling, Parasi, Mesir, Samudra, Banggala, Makasar, Pahang, Kalanten, Bangka, Buwun, Beten, Tulangbawang, Sela, Pasay, Parayaman, Nagara Dekan, Dinah, Andeles, Tego, Maloko, Badan, Pego, Malangkabo, Mekah, Buretet, Lawe, Saksak, Sembawa, Bali, Jenggi, Nusabini, Ngogan, Kanangen, Kumering, Simpang Tiga, Gumantung, Manumbi, Babu, Nyiri, Sapari, Patukangan, Surabaya, Lampung, Jambudipa, Seran, Gedah, Solot, Solodong, Indragiri, 
Tanjungpura, Sakampung, Cempa, Baluk, Jawa; sing sawatek paranusa ma sang jurubasa darmamurcaya tanya. (1987;86:XX).

\section{Peradaban Cina yang Tinggi}

Keluhuran peradaban bangsa Tiongkok tertulis dalam naskah Sanghyang Siksakandang Karesian(SSK). Peradaban Tiongkok tersebut dijadikan perumpamaan dan nasihat bagi seseorang yang pergi merantau ke suatu negeri dan ia mempelajari adat-istiadat negeri tersebut, ia dikatakan sebagai orang berhasil dalam perantauannya. Rujukan terhadap adat-istiadat yang baik itu adalah peradaban Cina.

Perumpamaan seseorang yang merantau dan lama tinggal di Cina, tahu adat-istiadat Cina, perilaku Cina, kehidupan Cina, kebaikan Cina. Mengenal tiga adatnya: rendah, menengah, dan tinggi. Mengetahui semua sabda sang prabu, sang rama, sang resi, bisa menggabungkan jiwa, ucapan, dan pikiran. Mengenal kenikmatan makanan, pandai berbusana, dan pandai memerintah dengan perkataan yang baik.

Ini ma upama janma tandang ka Cina. Heubeul mangkuk di Cina, nyaho di karma Cina, di tingkah Cina, di polah Cina, di karampesan Cina. Katemu na cara telu: kanista, madya, utama. Pahi nyaho di sabda sang prabu, sang rama, sang resi, bisa matitiskeun bayu, sabda, hidep. Nya mana nyaho di geuing, di upageuing, di parigeuing; yata tri geuing ngaranna. (1987;88:XXIII).

\section{Negeri Cina}

Hubungan Sunda dengan Tiongkok yang terjalin dalam waktu yang sangat lama tersebutkan dalam naskah Bujangga Manik (BM), Carita Parahiyangan (CP), dan Kawih Pangeuyeukan (KP) yang ditulis pada abad ke-16 dan 17. Kedua naskah tersebut menyebutkan Negeri Tiongkok sebagai Nusa Cina. Nusa Cina dalam naskah BM dikatakan sebagai negeri yang berdekatan di antara Nusa Dilih, Nusa Bini (Jepang), Nusa Keling, Nusa Jambri (Jambi), Jambudipa (India), Gedah (Kedah), dan Malaka. Hal ini ditunjukkan dalam kutipan yang berbunyi, "Nusa Dilih Nusa Bini, Nusa Keling Nusa Jambri, Nusa Cina Jambudipa,Nusa Gedah deung Malaka $(2009 ; 308: 1267-1270)$.

Dalam Kawih Pangeuyeukan (KP), Negeri Tiongkok juga disebut sebagai Nusa Cina. Pada bagian ini dikisahkan bahwa seorang dewi penghuni alat tenun itu merupakan gadis yang memiliki 
sifat kepertiwian. Ia sangat dimuliakan ketika berada di Nusa Cina dan memimpin ratusan ribu orang kasim (malawading).

Leuwih luput ti sakitu, lamun laksana dilaki, teu burung ruat na mala, reungeukeuneun urang opoy, ngaranna kapretiwian, acina kamuliyaan, samangsa di Nusa Cina, eta keti malawading. (2014;155-156:530-537).

Penyebutan Negeri Tiongkok dalam naskah Carita Parahiyangan (CP) yang ditulis pada akhir abad ke-16 menjelaskan peristiwa perang yang terjadi pada masa pemerintahan Raja Sanjaya. Sebagai raja kerajaan Galuh, Raja Sanjaya berusaha untuk meluaskan kekuasaannya dengan menundukkan beberapa negeri seperti Melayu, Kemir, Keling, Barus, dan Cina.

Ti inya Rahiyang Sanjaya nyabrang ka desa Malayu. Diprang di Kemir, eleh Rahiyangtang Gana. Diprang deui di Keling, eleh sang Sri Wijaya. Diprang ka Barus, eleh Ratu Jayadana. Diprang ka Cina, eleh Patih Sarikaladarma. Pulang Rahiyang Sanjaya ka Galuh ti sabrang. (1987/88;9:16Bb).

Luasnya kerajaan yang dibangun pada masa Raja Sanjaya juga diwarisi oleh saudara dari pihak neneknya, yaitu Rahiyangtang Kuku atau Seuweukarma Raja Kuningan. Setelah Sanjaya mangkat, Seuweukarma juga menaklukkan raja-raja Kemir, Melayu, Barus, Keling, Berawan, Cimara Upatah, dan Cina.

Rahiyangtang Gana Ratu di Kemir, Sang Sri Wijaya di Malayu, Sang Wisnu Jaya di Barus, Sang Brahmasidi di Keling, Patihnira Sang Kadarman di Berawan, Sang Mawuluasu di Cimara Upatah, Sang Pancadana Ratu Cina. Pahi kawisesa kena inya ku Rahiyangtang Kuku. (1987/88;10:45b).

\section{a. Cina sebagai Produsen Berkualitas Tinggi}

Naskah-naskah Sewaka Darma(SD), Sri Ajnyana (SA), Bujangga Manik (BM), Darma Jati (DJ), Kawih Pangeuyeukan (KP), dan Carita Ratu Pakuan (CRP) menyebutkan produk-produk unggulan berkualitas tinggi yang berasal dari Tiongkok. Produk-produk tersebut diantaranya kaca atau gelas kristal, kain, perak, besi, tembaga, emas, tempat sirih, tali, dan batu mulia.

Kaca merupakan produk Tiongkok yang paling banyak disebutkan dalam naskah Sunda Kuno. Kaca produk Tiongkok ini disebutkan sebagai kaca Cina. Jenis-jenis kaca yang disebutkan ada yang berupa kaca gelas atau kristal untuk tempat minyak wangi. 
burat wangi dina sabun, canggu dina ungkeb gading, paminyakan kaca Cina, isina lenga wangsana, $(1987 ; 28: 40)$.

Eunteung Jawa diparada, sisir gading batri ngukir, paminyakan kaca Cina, eusina lenga wangsana, kapur Barus dina сири (2009;316:1601-1605).

Kaca Cina juga digunakan untuk lantai rumah, dinding lorong, dan batu pembatas jalan di surga. Di dalam teks dikatakan bahwa orang yang menginjak lantai tersebut kaget dengan pijakan yang bening seperti air.

... datang ka bumi kanycana, kikis manik tihang demas, buruan sariga eunteung, naha guna kaca Cina, ditapak sarasa ngencong (1987;38:62).

Pantona kowari beusi, dipeundeutan ku tambaga, dilorongan ku salaka, kaca Cina eunteung omas, (2004;67:88-91).

Tihang gading beunang ngukir, tatapakan goong Jawa, dibalay ku kaca Cina, diselang ku batu kresna (2009;315:1580-1583).

Kaca Cina juga digunakan untuk perbandingan atau metafora dalam melukiskan kecantikan seorang gadis. Sinar mata gadis yang berbinar-binar dilukiskan dalam naskah Carita Ratu Pakuan (CRP) bagaikan kaca Cina.

irung kadi pala hurung, panon kadi kaca Cina, barentik na bulu panon, taktak taraju Jawaeun, (1987/88:15b:293-296).

Naskah-naskah Sunda Kuno juga menyebutkan produk Tiongkok yang berkualitas tinggi dan banyak digunakan oleh masyarakat Sunda pada masa itu adalah kain. Kain yang paling banyak dipakai adalah saputangan, selendang sutra, dan gorden rumah.

Satapih giringsing wayang, sakarembong lungsir keris, beunang nalepuh ku demas, sasalimbut sulam Baluk, sasalempay sado Cina, saamben gula manikem, (1987;31:47).

Ameng ta datang ti wetan, sakaen poleng puranteng, sasalimbut sulam Baluk, sasalempay sutra Cina, sapecut hoe walatung (2009;284:250-254).

Teumu Puah Aci Kuning, eukeur lungguh dina kasur, satapih giringsing wayang, saamben gula manikem, disasampay laka Cina, masalimbut laka Keling, (2009;267:684689).

Payung lungsir puncak gading, payung kertas puncak omas, payung hateup sutra Keling, galewer parada Cina, (2009;317:1745-1748). 
Produk Tiongkok yang berkualitas tinggi dalam naskah Sunda Kuno adalah perak Cina. Perak sebagai salah satu logam mulia di bawah emas digambarkan sebagai salah satu bahan pembuat rumah di surga. Bagian rumah yang menggunakan perak Cina adalah atap, waton (balaibalai), dan lantai.

Ti timur Batara Isora, kahangan pirak putih, tihangna pirak diukir, bahanna pirak sagala, dihateupan pirak Cina, dituruban ku pirak (1987;33:51).

Sadiri aing ti inya, milang-milang kasorgaan, jeueung aing tebeh wetan, meru ditihang salaka, dipiwaton pirak Cina, dideudeul ku beusi Keling, sarena salaka Keling, (2009;262:469-475).

asup ka bumi kancana, kana meru tumpang sanga, tihang omas jati rupa, hateupna sarba kancana, disarean pirak Cina, dideudeul ku pirak putih, imah maneuh dikarancang. (2009;270:791-797).

Besi adalah produk Tiongkok berkualitas yang disebutkan dalam naskah Sunda Kuno. Besi juga digunakan sebagai material pembangun rumah atau istana di surga. Besi Cina ini digunakan untuk membuat atap dan lantai istana.

Ti kaler Batara Wisnu, kahyangan miru hireng, tihangna beusi diukir, bahanna beusi sagala, dihateupan beusi Cina, disarean ku malela. (1987;33:52).

Nyoreang aing ngalerkeun, aya meru tumpang teulu, ditihangan ku malela, dihateupan tunjung putih, didadampar beusi Cina, dikikitir purasani, (2009;263:517-522).

Logam lain yang menjadi produk berkualitas tinggi dari Tiongkok adalah tembaga. Tembaga Cina yang disebutkan di dalam naskah Sunda Kuno digunakan sebagai lantai rumah atau istana di kayangan.

Ti kidul Batara Brahma, kahyangan warna mirah, tihangna tambaga diukir, bahanna tambaga sagala, dihateupan ku tambaga sukla, disarean tambaga Cina, didingding tambaga Keling. $(1987 ; 34: 54)$.

Aya deui ti sakitu, jeueung aing tebeh kidul, meru dihateup tambaga, tihangna tambaga sukla, sarena tambaga Cina, dijeujeutan omas Cina. (2009;263:488-493).

Logam mulia produk Tiongkok yang berkualitas adalah emas. Berbeda dengan perak yang digunakan untuk atap dan lantai, emas Cina digunakan untuk menghiasi ranjang atau peraduan di dalam istana dan surga. Ranjang tersebut diberi rantai atau jalinan tali dari emas. 
Ranjangna ditihang omas, beunang ngarancang ku mirah, disaréan omas ngora, dijeujeutan omas Cina, diwatonan mirah hinten, diturub ku pirak putih, (2009;270:807812)

Disarean ku panamar, dipiwaton omas kolot, diselang ku pirak apu, dijeujeutan omas Cina, diselang deung kawat Jawa. (2009;315:1590-1594).

Tempat sirih atau pekinangan juga merupakan salah satu produk berkualitas dari Tiongkok yang digunakan oleh putri-putri keraton. Naskah Bujangga Manik (BM) menyebutkan tempat sirih sebagi ebun Cina. Ebun yang digunakan oleh putri tersebut diberi hiasan dengan parada atau air perak dan merupakan pamuat atau upeti dari negeri seberang.

Teherna lungguh di kasur, nyangigirkeun ebun Cina, ebun Cina diparada, pamuat ti alas peuntas. (2009;285:287-290).

Tali yang diproduksi di Tiongkok adalah kenur Cina, atau sejenis tali yang sangat kuat untuk tali pancing atau layangan. Kenur Cina ini digunakan untuk melilit dan memperkuat bagian perahu atau kapal laut.

Apus dangdan hoe muka, pabaur hoe walatung, diselang deung hoe omas, tali bubut kenur Cina. (2009;300:911-914).

Mirah adalah batu mulia yang tertulis pada naskah Sunda Kuno. Kawih Pangeuyeukan (KP) menyebutkan bahwa kain yang indah adalah kain yang ditenun oleh gadis yang mengenal dewidewi penghuni alat tenun. Tenunan yang bagus tersebut salah satu bahannya menggunakan mirah Cina sebagai benang pakan.

tinun sindur sutra manik, milusian dasar beureum, dipakanan mirah Cina, disisian ku banyumas (2014:118:72-75).

susulaman tutulisan, dipakanan mirah Cina, disisian asri naga, pabeulit deung barayana $(2014 ; 120: 82-85)$.

\section{b. Cina sebagai Ahli Senjata}

Naskah Bujangga Manik memberi gambaran tentang kepiawaian orang Tiongkok dalam berperang. Di dalam kapal laut yang ditumpangi oleh Bujangga Manik, ia menemukan awak kapal berupa pasukan jurupanah yang berasal dari Tiongkok (jurupanah urang Cina).

jurubatu urang Lampung, jurumudi urang Jambri, juruwedil urang Bali, jurupanah urang Cina, jurutulup ti Malayu, (2009;300:923-927).

\section{c. Cina dan Politik}


Selain sebagai negeri yang menjadi mitra dalam berbagai interaksi sosial, ekonomi, dan budaya, Tiongkok juga disebutkan sebagai salah satu ancaman bagi kedaulatan negeri pada masa kerajaan Sunda masih berdiri. Naskah Amanat Galunggung menyatakan bahwa salah satu tempat yang harus benar-benar dijaga dari serangan musuh adalh kabuyutan Galunggung. Kabuyutan ini merupakan benteng terakhir kekuatan kerajaan bila dalam peperangan, istana sudah dikuasai oleh musuh. Beberapa negeri yang dianggap ancaman terhadap kedaulatan kerajaan Sunda adalah Jawa, Baluk, Cina, Lampung, dan negeri lain yang masih memiliki hubungan kekerabatan.

Teks tersebut merupakan nasihat Rakean Darmasiksa kepada putranya, Sang Lumahing Taman sebagai Rajaputra (Putra Mahkota) agar mempertahankan kabuyutan sebagai pertahanan terakhir dari serangan musuh. Dikatakan bahwa apabila kabuyutan tersebut dapat dikuasai oleh musuh maka harkat dan martabat sang putra mahkota sejajar dengan kulit musang di tempat sampah.

Lamun miprangkeuna kabuyutan na Galunggung, antuk na kabuyutan, awak urang na kabuyutan. Nu leuwih diparaspade, pa hi deung na Galunggung. Jaga beunangna kabuyutan ku Jawa, ku Baluk, ku Cina, ku Lampung, ku sakalih. Muliyana kulit lasun di jaryan, madan na rajaputra, antuk na beunang ku sakalih. (1987;120:2-4).

\section{d. Cina sebagai Acuan Keindahan}

Kawih Pangeuyeukan (KP) yang berisi ajaran tentang hakikat keterampilan bertenun memaparkan tentang keindahan kain tenun yang dibuat oleh seorang wanita mulia. Keindahan kain tenun itu salah satunya warna merah dan emas, bermotif naga dan burung yang sangat erat kaitannya dengan motif hiasan pada lukisan-lukisan dan kepercayaan masyarakat Tiongkok. Kain tenun yang memiliki warna dan motif demikian dikatakan sebagai milangeu Cina (menikmati keindahan Cina).

Beunang ngusap ku haremas, dingaran taluki wayang, diselang saca dewangga eta ngaran milangeu Cina (2014;120:92-95).

\section{e. Cina sebagai Pengusaha}

Kepiawaian orang Tiongkok dalam berniaga rupa-rupanya terekam juga di dalam naskah Sunda Kuno. Naskah Carita Ratu Pakuan (CRP) yang mengisahkan iring-iringan perpindahan Prabu Siliwangi dari keraton Kawali ke keraton Pakuan. Selama di perjalanan, Prabu Siliwangi menikahi beberapa putri dari kerajaan daerah yang dilaluinya. Naskah ini mencatat dua orang tokoh yang memakai nama belakang Cina yaitu Munding Cina dan Haning Cina. Kedua tokoh tersebut diperkirakan sebagai kakak beradik laki-laki dan perempuan keturunan Tiongkok. Munding Cina 
dikatakan sebagai pedagang yang baru pulang dari Lumajang, ia pandai berbicara dua bahasa dan merupakan orang kaya di Pabean.

Ahis Tuhan Jayasakti, seuweu Patih Sang Atus Wangi, Munding Cina pulang dagang, basa pulang ti Lumajang, sakelel midua basa, nu beunghar di Pabeyan (1987/88:1-2a:612)

seuweu Patih Sang Atus Wangi, Munding Cina pulang dagang, basa pulang ti Lamajang sakelet midua basa, nu beunghar di Pabeyan, (1970:22a-22b:418-423).

Tokoh yang kedua adalah perempuan pengiring pengantin yang bernama Haning Cina. Ia dikatakan sebagai putri dari seorang betari yang menjadi tarahan atau juragan perahu.

bur nu nurut lakiyan, Haning Cina Sari Wangi, sari putri batari, tarahan wang, seuweu Susuhunan Makabo (1970:14b:267-271).

\section{f. Cina sebagai Nama Ciri pada Fauna}

Naskah Sewaka Darma dalam kolofon penutupnya mengatakan bahwa teks tersebut ditulis oleh carik yang rendah hati. Ia menyampaikan permohonan maaf atas kesalahan dan kekurangan dalam pekerjaanya menulis. Kekhawatirannya akan akibat buruk (mahala) dari kealpaan selama menulis ia sampaikan dalam untaian metafora bahwa tulisan tersebut acak-acakan seperti jejak kepiting Cina.

Sang akwakwana mahala ka aing, lempurang dening sasaur, uracek loter kadi lacak yuyu Cina $(1987 ; 40: 66)$.

\section{g. Cina sebagai Nama Jenis Bunga}

Nama tanaman hias atau bunga yang tercatat pada naskah Sewaka Darma salah satunya adalah kembang Cina janaraya. Penelitian terhadap nama-nama tumbuhan dalam naskah Sunda Kuno memperkirakan kembang Cina janaraya adalah sejenis kembang sepatu atau Hibiscus Rosa-sinensis. Sedangkan areuy Cina diperkirakan sebagai bunga tali atau rincik bumi yaitu Quamoclit pennata (Ruhimat, 2014).

Kembang teleng bunga hireng, kasumba deung kapuracata, deung kembang jamaka, taluki saruni Keling, kembang Cina janaraya, siang kembang sokalarang, murub kembang hurungkanjut. (1987; 26:36)

Ti peuntas siang sorangan, ti sisi areuy janura, disela diareuy Cina, centam kadi wayangwayangan $(1987 ; 27: 37)$.

\section{Kesimpulan}


Hubungan Tiongkok dengan Sunda telah terjalin sejak sebelum abad ke-7 Masehi dengan adanya pengiriman utusan-utusan dari Tarumanagara ke Tiongkok. Hubungan Tiongkok dan Sunda mengalami masa perkembangan pada abad ke-16 dan 17 dengan bukti-bukti yang ditemukan pada naskah-naskah Sunda Kuno. Pengetahuan masyarakat Sunda pada abad ke-16 dan 17 tentang Tiongkok membuktikan bahwa mereka telah saling mengenal melalui bahasa, peradaban, produkproduk berkualitas tinggi, politik, dan kepandaian. Hubungan baik antara Tiongkok dan Sunda sebagaimana yang tertulis pada naskah-naskah Sunda Kuno merupakan amanat yang diwariskan oleh nenek moyang masyarakat Sunda agar generasi penerusnya saling mengenal dan hidup rukun dalam berbangsa dan bernegara.

\section{Daftar Pustaka}

Atja. 1970. Ratu Pakuan: Tjeritera Sunda-Kuno dari Lereng Gunung Cikuraj. Bandung: Lembaga Bahasa dan Sedjarah.

Danasasmita, Saleh. dkk. 1987. Sewaka Darma, Sanghyang Siksakandang Karesian, Amanat Galunggung: Transkripsi dan Terjemahan. Bandung: Bagian Proyek Penelitian dan Pengkajian Kebudayaan Sunda (Sundanologi).

Darsa, Undang Ahmad, Edi S. Ekadjati, dan Mamat Ruhimat. 2004. Darmajati: Naskah Lontar Kropak 423 (Transliterasi, Rekonstruksi, Suntingan, dan Terjemahan Teks). Bandung: Universitas Padjadjaran.

Noorduyn, J. - A. Teeuw. 2009. Tiga Pesona Sunda Kuna. (Terjemahan oleh Hawe Setiawan, Tien Wartini dan Undang Ahmad Darsa). Jakarta: Dunia Pustaka Jaya.

Ruhimat, Mamat, Aditia Gunawan, dan Tien Wartini. 2014. Kawih Pangeuyeukan: Tenun dalam Puisi Sunda Kuno dan Teks-teks Lainnya. Jakarta: Perpustakaan Nasional RI.

Ruhimat, Mamat, dkk. 2014. Fungsi dan Makna Kekayaan Flora pada Naskah Sunda Kuna. Bandung: Fakultas Ilmu Budaya Universitas Padjadjaran.

Soekmono, R. 1973. Pengantar Sejarah Kebudayaan Indonesia 2. Yogyakarta: Kanisius. Suriadiraja, 1932. "Karaman di Purwakarta" dalam Campakawarna. Batawi: Kantor Citak Gupernemen. 